\title{
CORRIGENDUM
}

\section{The bZIP transcription factor MdHY5 regulates anthocyanin accumulation and nitrate assimilation in apple}

Jian-Ping An, Feng-Jia Qu, Ji-Fang Yao, Xiao-Na Wang, Chun-Xiang You, Xiao-Fei Wang and Yu-Jin Hao

Horticulture Research (2017) 4, 17056; doi:10.1038/hortres.2017.56; Published online 4 October 2017

Correction to: Horticulture Research (2017) 4, 17023; doi:10.1038/ hortres.2017.23; published online 7 June 2017

Since the publication of this article, the authors have noticed an error in Figure 4, the correct Figure 4 is given here.

a

\begin{tabular}{|c|c|c|}
\hline CACGTG & CACGTG & MdMYB10 \\
\hline G-Box-1 & G-Box-2 & $\overrightarrow{\mathrm{ATG}}$ \\
\hline & & MdMYB10 \\
\hline & CGCGCG & \\
\hline
\end{tabular}
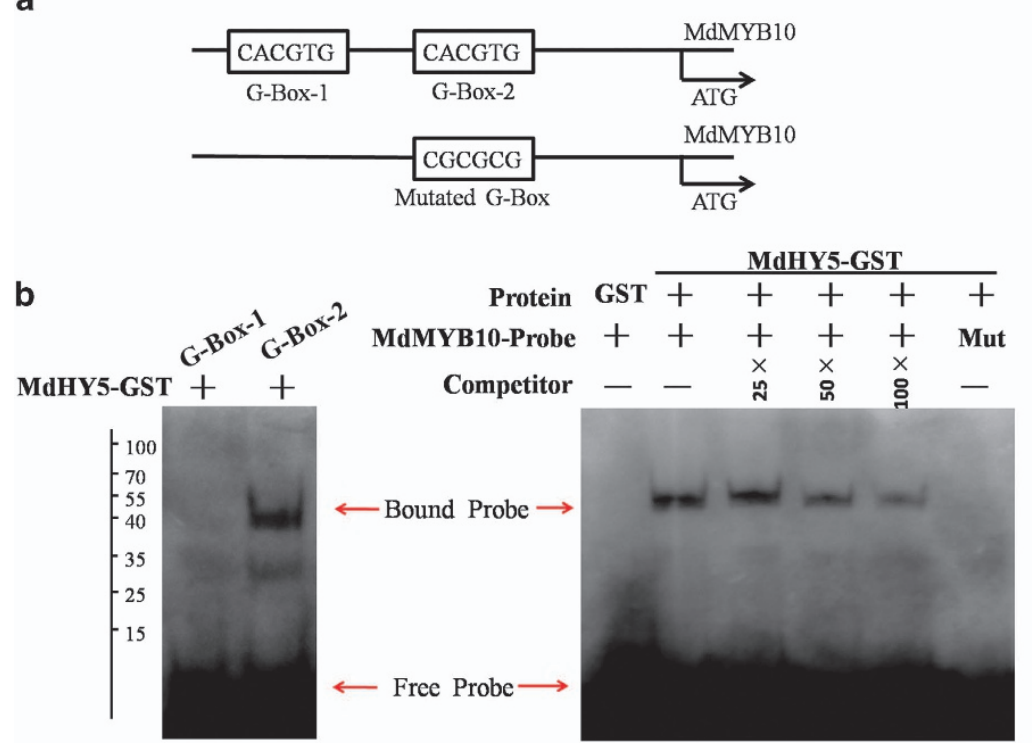

Figure 4.
These errors have now been rectified and the correct article appears in this issue. The html and online pdf versions have also been rectified and now carry the correct paper.

The authors would like to apologize for this error.
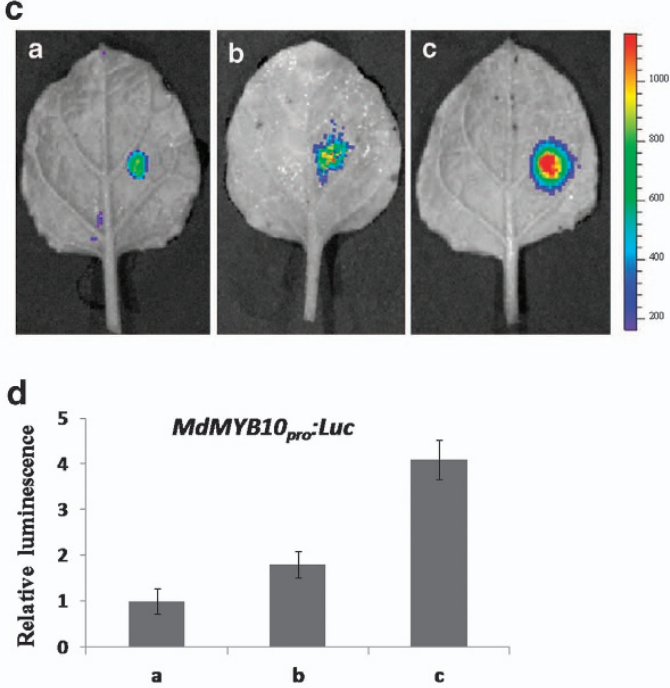